\title{
VEGETATION CONDITION INDEX: A POTENTIAL YIELD ESTIMATOR
}

\author{
S.K. Dubey ${ }^{*}$ Ashutosh Gavli, Neetu \& S.S. Ray \\ Mahalanobis National Crop Forecast Centre, Pusa Campus, New Delhi, India - sunil.dubey86@gov.in; \\ ashu.agricos@gmail.com; (neetu.ncfc, shibendu.ncfc)@nic.in
}

Commission III, WG III/10

KEY WORDS: Vegetation Condition Index, Remote Sensing, FASAL, Yield forecasting, NDVI

\begin{abstract}
:
Early yield assessment at local, regional and national scales is a major requirement for various users such as agriculture planners, policy makers, crop insurance companies and researchers. Current study explored a remote sensing-based approach of predicting the yield of Wheat, Kharif Rice and Rabi Rice at district level, using Vegetation Condition Index (VCI), under the FASAL programme. In order to make the estimates 14-years' historical database (2003-2016) of NDVI was used to derive the VCI. The yield estimation was carried out for 335 districts (136 districts of Wheat, 23 districts of Rabi Rice and 159 districts of Kharif Rice) for the period of 2016-17. NDVI products (MOD-13A2) of MODIS instrument on board Terra satellite at 16-day interval from first fortnight of peak growing period of crop were used to calculate the VCI. Stepwise regression technique was used to develop empirical models between VCI and historical yield of crops. Estimated yields are good in agreement with the actual district level yield with the $\mathrm{R}^{2}$ of, 0.78 for Wheat, 0.52 for Rabi Rice and 0.69 for Kharif Rice. For all the districts, the empirical models were found to be statistically significant. A large number of statistical parameters were computed to evaluate the performance of VCI-based models in predicting district-level crop yield. Though there was variation in model performance in different states and crops, overall, the study showed the usefulness of VCI, which can be used as an input for operational crop yield forecasting, at district level.
\end{abstract}

\section{INTRODUCTION}

Crop yield forecasting is necessary, particularly in countries that depend on agriculture as their main source of economy. Early yield assessment at regional and national scales is becoming increasingly important to many user-groups, e.g. agriculture planners and policy makers, crop insurance companies and researcher's community (Van Wart et al. 2013; Dadhwal and Ray 2000). It enables planners and decision makers to predict how much to import in case of shortfall or to export in case of surplus. Lack of quality agricultural statistics may lead to misallocation of scarce resources and policy formulations that fail to resolve critical development problems. Crop yield estimation in many countries is based on conventional procedures of data collection through experimentation. Such techniques are often subjective, costly, time consuming and are prone to large errors due to incomplete ground observations, leading to poor crop yield assessment (Sapkota et al. 2016). Various methods of yield estimation in India has been reported by Sud et al. (2016).

Remotely sensed crop data offer considerable opportunities for agricultural decision makers via the possible improvement in crop yield predictions and crop loss assessment (Lobell 2013). It has the potential and the capacity to provide spatial information at global scale of features and phenomena on earth on an almost real-time basis. Many countries had adopted the remote sensing-based crop yield forecast in operational system, some of the major agricultural programmes in the world monitoring agriculture are GEO Global Agricultural Monitoring (GLAM) (Inbal Becker-Reshef et al. 2010), Monitoring Agricultural Resources through Remote Sensing (MARS) (Gallego 1999), FAO Global Information and Early Warning System (GIEWS) (www.fao.org/giews/en/), China Crop Watch System (CCWS) (http://www.cropwatch.com.cn/).
GEOGLAM project (GEOGLAM, 2019) monitors real-time crop conditions and contributes national crop production forecasts (for wheat, soybeans, corn, and rice) computed by 30 national partners to the AMIS (Agricultural Market Information System) outlooks on a monthly basis. GIEWS - (Global Information and Early Warning System) of FAO utilizes remote sensing data and provide a valuable insight on water availability and vegetation health during the cropping seasons also provided regional production forecast. The MARS crop yield forecasting system (MCYFS) is used to monitor crop growth development, evaluate short-term effects of anomalous meteorological events, and provide monthly forecasts of crop yield and production (Van der Velde \& Nisini, 2019). RIICE (Remote sensing-based Information and Insurance for Crops in Emerging economies) produces accurate rice crop maps and yield forecasts (Setiyono et al. 2014) and quantifies production damage caused by natural disasters (http://www.riice.org).

India is one of the few countries which have well established system of crop yield estimation. Crop production forecasts in India using remotely sensed data started in early 1990s at Space Applications Centre (SAC), Ahmedabad under Crop Acreage and Production Estimation (CAPE) project (Navalgund et al. 1991). Currently, FASAL (Forecasting Agricultural output using Space, Agro-meteorology and Land-based observations) is a major programme of the Department of Agriculture, Cooperation and Farmers' Welfare, Ministry of Agriculture \& Farmers Welfare, aimed at pre-harvest crop production forecasting at district, state and national level (Ray et al. 2014a, Ray et al 2014b). Under FASAL project, crop area is estimated using remote sensing data and yield is estimated either using agro-meteorological, crop simulation or remote sensing-based

\footnotetext{
${ }^{*}$ Corresponding author
} 
models. FASAL deals with 8 major crops of the country, including the major food grain crops like Rice and Wheat.

For yield prediction of crops, it is necessary to achieve a very high accuracy and reliability. Remote sensing technology offers the high accuracy and reliability through the quantitative processing of satellite remote sensing data (Ferencz et al. 2004). Remote sensing-based yield estimation have already been proven as an effective alternative for conventional yield forecasting system (Dadhwal, \& Ray, 2000; Noureldin et al., 2013; Chen et al., 2011; Rahman et al., 2009; Rahman et al., 2012; Wang et al., 2010; Haung et al., 2013; Dubey et al., 2018, Dubey et al., 2017).

One of the most popular remote sensing-based indices used for crop assessment is Normalized Difference Vegetation Index (NDVI), which is the ratio of (NIR-R)/(NIR+R), where NIR \& $\mathrm{R}$ are reflectance in near infra-red and red band. The NDVI has been found to be highly related with leaf area index, crop condition and fraction of absorbed Photosynthetically active radiation. There have been many works to develop models crop yield using NDVI (Rasmussen, 1992; Murthy, et al. 1996; Burke \& Lobell 2017; Bose, et al., 2016; Chlingaryan, et al., 2018). However, the crops with indeterminate growth a bit and the crops where LAI is not strongly related to final yield, NDVI performance in yield prediction have been poor (Ray et al.1999).

Vegetation Condition Index (VCI), as suggested by Kogan (1998), is an indicator of the vigour of the vegetation cover, as a function of NDVI minima and maxima for a given time period and a given land area. It normalizes NDVI based on its value over many years and results in a consistent index for different land cover types. VCI has been considered as an ideal candidate in the index-based insurance because it is highly correlated with crop yields and hence able to accurately track yield losses (Hochrainer-Stigler et al. 2014). Dubey et al. (2018) used VCI for district-level Sugarcane yield estimation under the FASAL project and observed that The VCI derived from long-term lowresolution satellite data has ability to explain the sugarcane yield variability up to $86 \%$, in some cases where as in majority of cases, the variability explained was more than $60 \%$.

Though the remote sensing technology has proven its ability in crop yield forecasting, still the use of vegetation index in operational yield forecasting of food grain crops at district level is unexplored. Considering the facts, present study has been planned to evaluate the role of VCI for district level yield estimation of major (Rice \& Wheat) crops grown in India.

\section{METHODOLOGY}

\subsection{Study area}

VCI based yield estimates have been generated and evaluated for total 439 districts, which includes 222 districts of Wheat in 9 states, 32 districts of Rabi Rice in 5 states, 31 districts of Samba Rice in 1 state and 154 districts of Kharif Rice in 13 states. The states /districts selected in the study are major growing states /districts covers $\sim 80 \%$ of total concerned crop production. Name of the states are given in Table 1 along with model statistics.

\begin{tabular}{|c|c|c|c|c|c|}
\hline State & $\begin{array}{c}\text { Estimate } \\
\text { d Yield } \\
(\mathrm{kg} / \mathrm{ha})\end{array}$ & $\begin{array}{c}\mathrm{F} \\
\text { Values }\end{array}$ & $\mathrm{R}^{2}$ & $\begin{array}{l}\text { Adjusted } \\
\mathrm{R}^{2}\end{array}$ & $\begin{array}{c}\text { Number } \\
\text { of } \\
\text { District } \\
s\end{array}$ \\
\hline \multicolumn{6}{|c|}{ Wheat } \\
\hline Bihar & $\begin{array}{l}803- \\
3341\end{array}$ & $2-36$ & $\begin{array}{c}0.19- \\
0.89\end{array}$ & $\begin{array}{c}0.11- \\
0.86\end{array}$ & 38 \\
\hline Gujarat & $\begin{array}{c}2197- \\
3763\end{array}$ & $5-35$ & $\begin{array}{c}0.37- \\
0.85\end{array}$ & $\begin{array}{l}0.3- \\
0.82\end{array}$ & 8 \\
\hline Himachal & $1681-$ & & $0.43-$ & $0.37-$ & \\
\hline Pradesh & $\begin{array}{c}2510 \\
2480-\end{array}$ & $4-51$ & $\begin{array}{c}0.92 \\
0.39-\end{array}$ & $\begin{array}{l}0.91 \\
0.2-\end{array}$ & 7 \\
\hline Haryana & 5489 & $2-60$ & 0.98 & 0.97 & 19 \\
\hline Madhya & $1408-$ & & $0.27-$ & $0.19-$ & \\
\hline Pradesh & $\begin{array}{c}4440 \\
4100-\end{array}$ & $3-84$ & $\begin{array}{c}0.96 \\
0.41-\end{array}$ & $\begin{array}{c}0.94 \\
0.12-\end{array}$ & 49 \\
\hline Punjab & $\begin{array}{c}5513 \\
1654-\end{array}$ & $2-19$ & $\begin{array}{c}0.91 \\
0.26-\end{array}$ & $\begin{array}{c}0.83 \\
0.12-\end{array}$ & 17 \\
\hline Rajasthan & $\begin{array}{c}4308 \\
1004-\end{array}$ & $\begin{array}{c}1-33 \\
12-\end{array}$ & $\begin{array}{c}0.94 \\
0.58-\end{array}$ & $\begin{array}{c}0.88 \\
0.54-\end{array}$ & 23 \\
\hline Uttarakhand & 4277 & 16 & 0.8 & 0.76 & 4 \\
\hline Uttar & $1911-$ & $2-$ & $0.38-$ & $0.21-$ & \\
\hline Pradesh & 4631 & 198 & 0.99 & 0.98 & 57 \\
\hline \multicolumn{6}{|c|}{ Rabi Rice } \\
\hline $\begin{array}{l}\text { Andhra } \\
\text { Pradesh }\end{array}$ & $\begin{array}{c}3378- \\
4432\end{array}$ & $\begin{array}{c}7- \\
275\end{array}$ & $\begin{array}{c}0.45- \\
0.96\end{array}$ & $\begin{array}{c}0.39- \\
0.96\end{array}$ & 6 \\
\hline Telangana & $\begin{array}{c}2551- \\
3940\end{array}$ & $4-32$ & $\begin{array}{c}0.32- \\
0.89\end{array}$ & $\begin{array}{c}0.25- \\
0.86\end{array}$ & 5 \\
\hline Karnataka & $\begin{array}{c}2071- \\
5186\end{array}$ & $1-15$ & $\begin{array}{c}0.38- \\
0.79\end{array}$ & $\begin{array}{c}0.18- \\
0.74\end{array}$ & 4 \\
\hline Odisha & $\begin{array}{c}1702- \\
4810\end{array}$ & $\begin{array}{c}16- \\
56\end{array}$ & $\begin{array}{l}0.7- \\
0.94\end{array}$ & $\begin{array}{l}0.65- \\
0.93\end{array}$ & 8 \\
\hline $\begin{array}{l}\text { West } \\
\text { Bengal }\end{array}$ & $\begin{array}{c}2907- \\
4015 \\
\end{array}$ & $3-34$ & $\begin{array}{c}0.24- \\
0.89 \\
\end{array}$ & $\begin{array}{c}0.17- \\
0.86 \\
\end{array}$ & 9 \\
\hline \multicolumn{6}{|c|}{ Samba Rice } \\
\hline Tamil Nadu & $\begin{array}{c}1476- \\
5445\end{array}$ & $\begin{array}{c}1- \\
152 \\
\end{array}$ & $\begin{array}{c}0.22- \\
0.97\end{array}$ & $\begin{array}{c}0.14- \\
0.97\end{array}$ & 31 \\
\hline \multicolumn{6}{|c|}{ Kharif Rice } \\
\hline $\begin{array}{l}\text { Andhra } \\
\text { Pradesh }\end{array}$ & $\begin{array}{c}1938- \\
3654\end{array}$ & $5-19$ & $\begin{array}{l}0.24- \\
0.82\end{array}$ & - & 4 \\
\hline Assam & $\begin{array}{l}984- \\
2309\end{array}$ & $7-50$ & $\begin{array}{l}0.32- \\
0.88\end{array}$ & - & 15 \\
\hline Bihar & $\begin{array}{c}1050- \\
3025\end{array}$ & $6-56$ & $\begin{array}{c}0.18- \\
0.86\end{array}$ & - & 19 \\
\hline Chhattisgarh & $\begin{array}{c}1003- \\
3119\end{array}$ & $7-17$ & $\begin{array}{c}0.22- \\
0.79\end{array}$ & - & 9 \\
\hline Haryana & $\begin{array}{c}1717- \\
3887\end{array}$ & $7-14$ & $\begin{array}{c}0.31- \\
0.92\end{array}$ & - & 8 \\
\hline Jharkhand & $\begin{array}{c}1614- \\
3811 \\
1539-\end{array}$ & $6-54$ & $\begin{array}{c}0.18- \\
0.96 \\
0.43-\end{array}$ & - & 13 \\
\hline Karnataka & 3223 & $7-21$ & 0.91 & - & 8 \\
\hline Madhya & $896-$ & & $0.18-$ & & \\
\hline Pradesh & $\begin{array}{l}3222 \\
959-\end{array}$ & $6-17$ & $\begin{array}{c}0.79 \\
0.28-\end{array}$ & - & 7 \\
\hline Orissa & $\begin{array}{c}2556 \\
2999-\end{array}$ & $5-29$ & $\begin{array}{l}0.97 \\
0.31-\end{array}$ & - & 26 \\
\hline Punjab & $\begin{array}{c}4875 \\
2583-\end{array}$ & $6-29$ & $\begin{array}{c}0.86 \\
0.34-\end{array}$ & - & 6 \\
\hline Telangana & 3788 & $2-43$ & 0.67 & - & 5 \\
\hline Uttar & 1577 - & & $0.21-$ & & \\
\hline Pradesh & 2947 & $6-41$ & 0.88 & - & 27 \\
\hline West & $2220-$ & & $0.17-$ & & \\
\hline Bengal & 3089 & $7-25$ & 0.77 & - & 7 \\
\hline
\end{tabular}

Table 1: District wise ranges of Yield and statistical parameters 


\subsection{Data used}

\subsubsection{Crop map generation}

For kharif Rice, three Dates of RISAT-1 SAR (Synthetic Aperture Radar) MRS (Medium Resolution ScanSAR) mode data were used for acreage estimation. This satellite data is available once in every 25 days for the same area. Data pertaining to three such successive dates for each area has been used for acreage estimation. Dates of data acquisition for Punjab \& Haryana ranges from June 19 to Aug 22, 2016 and for rest of the states from July 03 to September 30, 2016. Total 691 RISAT-1 MRS scenes ( $115 \times 115 \mathrm{~km} 2)$ were used for the study. Stratified sample segment method and logical modelling classification approach was used for image analysis using 3271 Ground Truth (GT) sites collected by State Agriculture Departments. Rabi Rice map was generated using Sentinel-1 SAR (Synthetic Aperture Radar) data of $20 \mathrm{~m}$ resolution. This satellite data is available once in every 10 days for the same area. Data pertaining to three/four such successive dates (between mid-December and end of Feb) for each area has been used. Additionally, Landsat-8 OLI (30m) and Sentinel-2 MSI $(10 \mathrm{~m})$ data were also used for few districts. Samba Rice was estimated using Sentinel-1(SAR, $20 \mathrm{~m}$ resolution) from November 18, 2016 to January 10, 2017 data (Total 18 scenes).

For wheat crop map, single-date Resourcesat-2 LISS-III ( $24 \mathrm{~m}$ Resolution) data during the period 24 February to 07 March, 2017 have been used for acreage estimation. Wherever cloud free LISS III data was not available, single-date Sentinel-2(10m resolution) or Landsat (30 $\mathrm{m}$ resolution) data have been used. Supervised maximum likelihood classification approach was followed for image analysis using 2264 GT sites collected by state agriculture departments. After classification of the crop using satellite data, state-wise crop maps were prepared. These crops maps were used for generating crop specific vegetation indices for different districts. and minimum NDVI are the conceivable limits of the vegetation vigour, for a particular area and period, over the several years considered. When the current year NDVI is compared with the maximum and the minimum values, it helps in getting a fair idea of the present status of vegetation compared to its trend. Vegetation Condition Index (VCI) helps in isolating the short-term weather signals in the NDVI from the long-term ecological signal. The VCI of NDVI is defined as (Kogan 1998).

$$
V C I=\left(\frac{N D V I_{\text {current }}-N D V I_{\text {min }}}{N D V I_{\max }-N D V I_{\min }}\right) \times 100
$$

where, $\mathrm{NDVI}_{\mathrm{I}}$ is the NDVI at current time, $\mathrm{NDVI}_{\min }$ is the historical minimum NDVI for the same location and same period, and $\mathrm{NDVI}_{\max }$ is the historical maximum NDVI.

In present study, 14-year historical database (2003-2016) of NDVI was used to derive the VCI. The VCI images were overlaid with crop maps to generate crop specific VCI values. District-level crop maps were overlaid on the VCI images to get average (of all pixels in the district) VCI values for the districts. Thus, fortnight crops (Rice, Wheat) VCI values for each district, for 14 years, were derived. District-wise historical yield (2003-2015) data of concerned crops were taken from Directorate of Economics and Statistics (DES), Government of India and the State Agriculture Departments. The yields were used as dependent variable to develop the model. Correlation analysis was carried out between fortnightly VCI values and the crop yield. Empirical relation between yield and VCI for each district was derived using stepwise multiple linear regression technique, as defined by Agrawal (2011). Stepwise regression is a method of fitting regression models in which the choice of predictive variables is carried out by an automatic procedure. In each step, a variable is considered for addition to or subtraction from the set of explanatory variables based on pre-specified criterion (e.g. $F$ value). For this purpose, SPSS v.16.0

\begin{tabular}{|c|c|c|c|c|c|c|c|c|c|}
\hline \multirow{2}{*}{ Statistics } & \multicolumn{2}{|c|}{$\begin{array}{l}\text { Kharif Rice Yield } \\
(\mathrm{kg} / \mathrm{ha})\end{array}$} & \multicolumn{2}{|c|}{$\begin{array}{l}\text { Wheat Yield } \\
\text { (kg/ha) }\end{array}$} & \multicolumn{2}{|c|}{$\begin{array}{l}\text { Samba Rice Yield } \\
\text { (kg/ha) } \\
\text { Estimate }\end{array}$} & \multicolumn{3}{|c|}{$\begin{array}{l}\text { Rabi Rice Yield } \\
(\mathrm{kg} / \mathrm{ha})\end{array}$} \\
\hline & Estimated & Actual & Estimated & Actual & $\begin{array}{l}\text { Estimate } \\
\text { d }\end{array}$ & Actual & stimated & & Actual \\
\hline Standard Deviatic & 1031.5 & 1101.3 & 1006.5 & 920.4 & 1397.2 & 1156.7 & & 634.0 & 549.0 \\
\hline Standard Error & 93.0 & 99.3 & 86.6 & 79.2 & 338.9 & 280.5 & & 135.2 & 117.0 \\
\hline Skewness & 0.7 & 0.3 & 0.2 & 0.2 & 0.1 & -0.3 & & -0.3 & -0.4 \\
\hline Kurtosis & -0.4 & -1.1 & -0.7 & -0.9 & -1.4 & -1.1 & & 0.9 & -0.9 \\
\hline
\end{tabular}

Table 2: Descriptive statistics of estimated vs Actual yield (kg/ha)

\subsubsection{Vegetation Condition Index}

MODIS NDVI product (MOD13A2), available at every 16 days at $1 \mathrm{~km}$ spatial resolution as a gridded level-3 product in the Sinusoidal projection from the period of 2003-2016, was used to derive the Vegetation Condition Index. Level-II Land Use Land Cover (LULC) maps were taken from National Remote Sensing Centre (NRSC) for the year 2012 which is available on 1:50,000 scale derived using multitemporal Resourcesat 2 terrain corrected LISS III data. District shape files were used for demarcation of district boundary and calculation of district mean of NDVI. Under ideal conditions of good rainfall, adequate nutrients and management inputs, the crop in a region could grow to its maximum vigour, producing maximum NDVI for that year. On the contrary, in a drought year, less rainfall and inadequate inputs result in very low NDVI. This maximum (statistical package) was used. The models developed for each district were used to estimate district-level crop's yield for

2016-17 using that year's district-level VCI values. The detailed methodology of yield estimation is described in (Dubey et al. 2018).

\subsubsection{Model validation}

The model validation has been carried out by checking the accuracy of estimated yield against the observed yield obtained from Directorate of Economics and Statistics or State Agricultural Statistical Agencies). Various statistical parameters, R ${ }^{2}$, RMSE-root-mean-square error (Fox 1981), NMSE- normalized mean-squared error (Kumar et al. 1993), FB-fractional bias (Kumar et al. 1993) Modeling efficiency (Greenwood et al., 1985) and d- index of agreement (Willmott and Wicks 1980). Brief description of these statistical procedure is available in (Dubey et al. 2018). 


\section{RESULTS AND DISCUSSION}

\subsection{Model development}

The regression based statistical models were developed using fortnightly VCI as independent variable and observed yield obtained from DES as a dependent variable. The model parameters i.e. $\mathrm{F}$ value, $\mathrm{R}^{2}$ and Adjusted $\mathrm{R}^{2}$ is presented in Table 1 . The results revealed that the $F$ Values which is often used for comparing statistical models that have been fitted to a data set, in order to identify the model that best fits the population from which the data were sampled. In case of Wheat $\mathrm{R}^{2}$ ranged from 0.20 to 0.99 in among the study districts. In the states like Gujarat, Haryana, Punjab, Uttar Pradesh, Himachal Pradesh and Uttarakhand the values of $R^{2}$ is within the acceptable range. In case of Rajasthan, Bihar and Madhya Pradesh the values of $\mathrm{R}^{2}$ goes below the 0.3 (in few districts), though the model was significant $(\mathrm{p}=0.05)$. In Madhya Pradesh the reason of poor fitting of model may be due to higher year wise yield variation in the data obtained from DES.

In case of Rabi rice $\mathrm{R}^{2}$ ranges from 0.24 to 0.96 . It is evident from the table 3 that in the states like Andhra Pradesh and Odisha, the values of correlation coefficient were good which elaborates that the estimates derived from VCI method were in good agreement with the DES estimates. Samba Rice grown only in Tamilnadu states consist of 31 districts. The districts wise model was good in agreement and $\mathrm{R}^{2}$ ranged between 0.22-0.97.

Similarly, in case of Kharif rice the model is in good agreement with the VCI. $\mathrm{R}^{2}$ ranges between 0.17 to 0.96 . model developed for the states like Bihar, Jharkhand, Chhattisgarh, West Bengal and Uttar Pradesh is relatively poor in agreement in comparison to other states. This may be due to intra season sowing variability. In Madhya Pradesh the poor agreement of models in few districts is again may be due to higher yield (DES) variability.

\subsection{General yield statistics}

Descriptive statistics of entire study districts presented in Table 2 revealed that the average estimated yield of Kharif Rice is $2395.6 \mathrm{~kg} / \mathrm{ha}$ against the estimated yield of $2560 \mathrm{~kg} / \mathrm{ha}$, average estimated yield of wheat is $3322.3 \mathrm{~kg} / \mathrm{ha}$ against the actual yield of $3511 \mathrm{~kg} / \mathrm{ha}$. Rabi Rice yield (both estimated and actual) is quite higher in comparison to Kharif Rice and Samba Rice, it is already being reported that the Rabi rice yield is higher in comparison to Kharif Rice (Anonymous, 2019). Standard error for Actual yield of Samba Rice is higher in comparison to Kharif Rice and Rabi rice, it may be due to smaller population size $(n=31)$. The values for asymmetry and kurtosis lies between -2 and +2 are considered acceptable in order to prove normal univariate distribution (George \& Mallery, 2010) in our estimates the values are well within the range.

\subsection{Model validation}

In order to validate the model accuracy of estimated $v s$. actual yield has been quantified using various statistical procedures like $\mathrm{R}^{2}$, RMSE-root-mean-square error, NMSE- normalized mean-squared error, FB-fractional bias, EF-Modeling efficiency and d- index of agreement. The result of model validation is given in Table 3 and graphically depicted in Figure 1. Over all the results indicates that the estimates are in agreement with actual yield.

The $\mathrm{R}^{2}$ between the estimated and observed yield indicates that the predicted yield is good in agreement with actual yield except in Samba Rice and Rabi Rice. RMSE indicates the higher error in case of Samba Rice where as lowest in case of kharif Rice. Normalized mean-square error (NMSE), and Fractional Bias (FB) which should have been ideally close to zero, was very low for all the crops, in general. Index of agreement between the predicted yield which should be $0-1$ is well within the range. The lowest limit of FB, RMSE, NMSE, $\mathrm{EF}, \mathrm{d}$ and $\mathrm{FB}$ is 0 that means full adherence between model estimates and measures values. Overall, all the validation procedure agrees with the model, only the poor performance noticed in case of Samba Rice. This may be due to sudden drop

\begin{tabular}{ccccc}
\hline Index & $\begin{array}{c}\text { Kharif } \\
\text { Rice }\end{array}$ & Wheat & $\begin{array}{c}\text { Samba } \\
\text { Rice }\end{array}$ & $\begin{array}{c}\text { Rabi } \\
\text { Rice }\end{array}$ \\
\hline $\begin{array}{c}\text { Estimated Yield } \\
(\mathrm{kg} / \mathrm{ha})\end{array}$ & 2395.6 & 3322.3 & 3443.6 & 3614.4 \\
Observed Yield (kg/ha) & 2560.3 & 3703.5 & 2565.1 & 3530.7 \\
$\mathrm{R}^{2}$ & 0.69 & 0.78 & 0.55 & 0.54 \\
RMSE & 13.3 & 25.6 & 157.8 & 14.8 \\
NMSE & 0.1 & 0.018 & 0.2 & 0.02 \\
EF & 0.7 & 0.6 & -0.3 & 0.3 \\
$\mathrm{~d}$ & 0.9 & 0.9 & 0.8 & 0.9 \\
$\mathrm{FB}$ & -0.1 & -0.1 & 0.3 & 0.0 \\
\hline
\end{tabular}

of VCI value in few districts during the October month peak growing period. The VCI profile of the districts having good and poor $\mathrm{R}^{2}$ is depicted in Figure 2.

Table 3: model validation parameters
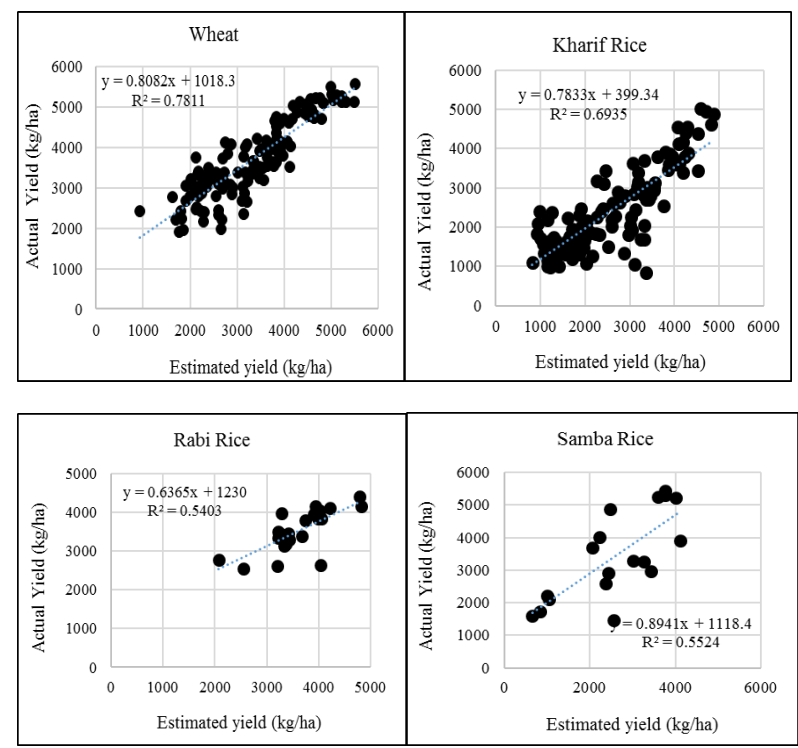

Figure 1: District wise Actual vs Estimated yield (kg/ha) of Wheat, Kharif Rice, Rabi Rice and Samba rice. 


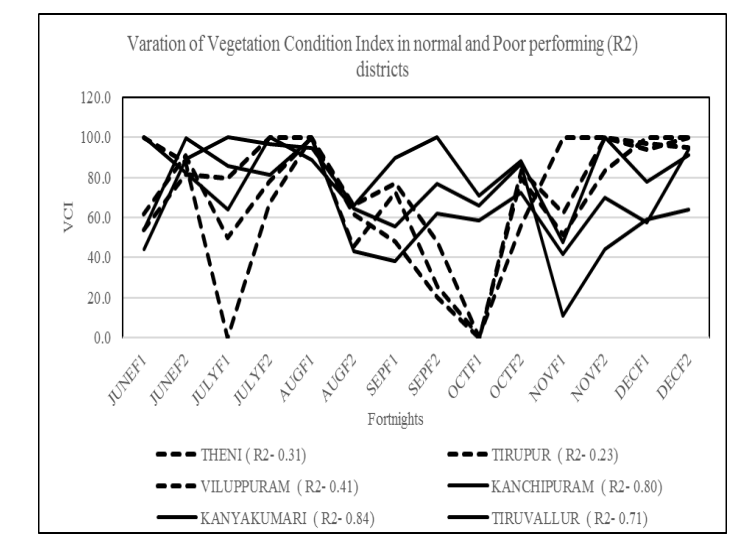

Figure 2: Fortnightly variation of VCI in good and Poor R2 districts of Samba Rice

\section{CONCLUSION}

This study was carried out to explore the suitability of satellite remote sensing-based index for operational district-level yield forecast of major food grains i.e. Rice \& Wheat. The Vegetation Condition Index (VCI) derived from long-term lowresolution satellite data was found to explain the district level yield variability up to $78 \%$ in Wheat up to $70 \%$ in Kharif Rice, $54 \%$ Rabi Rice and 55\% in Samba Rice. This is unique of its kind, since the district level yield forecast model using satellite remote sensing has not been developed yet, especially for Indian continent. In majority of cases, estimated yield was good in agreement with Actual yield. This study indicates the performance of VCI as an estimator is quite good for food grain crops.

\section{ACKNOWLEDGEMENTS}

The work was carried out under the FASAL project of Directorate of Economics \& Statistics of Department of Agriculture, Cooperation \& Farmers' Welfare (DAC \& FW). Authors are thankful to the Secretary, DAC\&FW for his strong support for the work. Data provided by the State Agriculture Departments is thankfully acknowledged.

\section{REFRENCES}

Anonymous (2019) http://agropedia.iitk.ac.in/content/ricegenreral-account-package-practice-production (accessed on 10 January 2019)

Chen, C.; Quilang, E.J.P.; Alosnos, E.D.; Finnigan, J. Rice area mapping, yield, and production forecasting for the Province of Nueva Ecija using RDARSAT imagery. Can. J. Remote Sens. 2011, 37, 1-16

Dadhwal, V. K., \& Ray, S. S. (2000). Crop Assessment using remote sensing-Part-II: Crop condition and yield assessment. Indian Journal of Agricultural Economics, 55(2), 55.

Dubey, S. K., Gavli, A. S., Yadav, S. K., Sehgal, S., \& Ray, S. S. (2018). Remote Sensing-Based Yield Forecasting for Sugarcane (Saccharum officinarum L.) Crop in India. Journal of the Indian Society of Remote Sensing, 46(11), 1823-1833.
Dubey, S.K., Gavli, Ashutosh, S.K. Diwakar, Neetu \& Ray, S.S. (2017). Use of vegetation condition index for rice yield forecasting. In 38th Asian conference on remote sensingSpace applications: Touching human lives, ACRS 2017, October 2017, New Delhi.

Ferencz, C., Bognar, P., Lichtenberger, J., Hamar, D., Tarcsai, G., Timár, G., ... \& Ferencz, O. E. (2004). Crop yield estimation by satellite remote sensing. International Journal of Remote Sensing, 25(20), 4113-4149.

GEOGLAM, 2019. Crop Monitor, https://cropmonitor.org/ (accessed 10 January 2019).

Huang, J.X.; Wang, X.; Li, H.; Tian, Z. Remotely sensed rice yield prediction using multi-temporal NDVI data derived from NOAA's AVHRR. PLoS One 2013, 8, e70816.

Kelly, V., Hopkins, J., Reardon, T. \& Crawford, E. 1995. Improving the measurement and analysis of African agricultural productivity: Promoting complementarities between micro and macro data. International Development Paper No. 16, East Lansing, Michigan, USA: Michigan State University.

Noureldin, N.A.; Aboelghar, M.A.; Saudy, H.S.; Ali, A.M. Rice yield forecasting models using satellite imagery in Egypt. Egypt. J. Remote Sens. Space Sci. 2013, 16, 125-131

Rahman, A.; Khan, K.; Krakauer, N.Y.; Roytman, L.; Kogan, F. Use of remote sensing data for estimation of Aman rice yield. Int. J. Agric. For. 2012, 2, 101-107.

Rahman, A.; Roytman, L.; Krakauer, N.Y.; Nizamuddin, M.; Goldberg, M. Use of vegetation health data for estimation of Aus rice yield in Bangladesh. Sensors 2009, 9, 2968-2975.

Ray, S. S., Neetu, Mamatha, S. \& Gupta, S. (2014a). Use of remote sensing in crop forecasting and assessment of impact of natural disasters: Operational approaches in India. In M. K. Srivastava (Ed.) Proceedings of the FAO expert meeting on crop monitoring for improved food security, Vientiane, Lao PDR; 17 February 2014. RAP Publication 2014/28. FAO and ADB, 2015. pp. 111-112.

Ray, S. S., Sesha Sai, M. V. R., \& Chattopadhyay, N. (2014b). Agricultural drought assessment: Operational approaches in india with special emphasis on 2012. In K. Ray, M. Mohapatra, B. K. Bandyopadhyay, \& L. S. Rathore (Eds.), High-impact weather events over the SAARC region (pp. 349-364). Berlin: Springer.

Setiyono, T., Nelson, A., \& Holecz, F. (2014). Remote sensingbased crop yield monitoring and forecasting. Crop monitoring for improved food security.

Sud, U. C., Ahmad, T., Gupta, V. K., Chandra, H., Sahoo, P. M., Aditya, K., ... \& Biswas, A. (2015). Research on Improving Methods for Estimating Crop Area. Yield and Production under Mixed, Repeated and Continuous Cropping ICAR-Indian Agricultural Statistics Research Institute New Delhi, India, $119 p p$

Van der Velde, M., \& Nisini, L. (2019). Performance of the MARS-crop yield forecasting system for the European Union: Assessing accuracy, in-season, and year-to-year improvements from 1993 to 2015. Agricultural Systems, 168, 203-212.

Wang, Y.P.; Chang, K.W.; Chen, R.K.; LO, J.C.; Shen, Y. Large-area rice yield forecasting using satellite imageries. Int. J. Appl. Earth Obs. Geoinf. 2010, 12, 27-35. 